\title{
Energy consumption in an urban wastewater treatment plant: the case of Murcia Region (Spain)
}

\author{
Arturo Albaladejo ${ }^{\mathrm{a}}$, Arturo Trapote ${ }^{\mathrm{a}}$ and Pedro Simón ${ }^{\mathrm{b}}$ \\ ${ }^{a}$ Department of Civil Engineering, University of Alicante, Alicante, Spain \\ ${ }^{b}$ Murcia Region Wastewater Sanitation and Treatment Agency (ESAMUR), Murcia, Spain
}

\begin{abstract}
Of all the costs associated with the operation and maintenance of wastewater treatment plants (WWTPs), those associated with energy use tend to be the most significant. From this point of view, it is hence logical that energy efficiency and saving strategies should be one of the current focuses of debate amongst those involved with the management of WWTPs. The present study's objective is to determine the correlation between size and energy consumption for a WWTP. To this end, 90 WWTPs currently in service were analyzed and their energetic impact quantified in terms of $\mathrm{kWh}$ per $\mathrm{m}^{3}$ of water treated. The results obtained demonstrate that energy consumption ratio increases as the size of WWTPs decreases, either in terms of treatment volume or population equivalent served.
\end{abstract}

Keywords: urban wastewater treatment plant; management of WWTPs; energy costs; energy efficiency; energy consumption.

\section{Introduction}

The energy consumption in a WWTP varies according to the size of the same, the pollutant load of influent, the type of treatment and the technology used, so the energy cost will vary from one to another. However, the energy consumed in a WWTP is mainly electric, except in large cogeneration facilities, and is fundamentally used for: pumps, blowers and/or aerators, digester heating, dewatering sludge by centrifugation, beltfilters press or filter presses, disinfection by ultraviolet, and deodorization systems.

Within the costs of operation and maintenance of the WWTPs the energy cost is the greatest of all. This paper examines the case of Spain, where that cost accounts for over $40 \%$ of the total operating costs (Castell et al., 2011). In addition, recent studies have manifested that this percentage will increase in line with the forecasted general increase in energy costs (Albaladejo and Trapote, 2013).
The objective of this study is to determine the correlation between size and energy consumption for an urban WWTP. With such aim, 90 WWTPs in service were analyzed, and its energy consumption in terms of $\mathrm{kWh} / \mathrm{m} 3$ of treated water was quantified.

It was found that energy consumption ratio increases as the size of WWTPs decreases, and that there are similar functional relationships between the ratio of energy consumption and the size of the WWTP, expressed this both in volume of treated water or in equivalent population served.

\section{Methodology}

The study encompassed 90 WWTPs in service throughout the Murcia Region (Spain). The majority were extended aeration type plants with nutrient removal processes (predominantly Nitrogen removal) and tertiary treatment for water reuse (Figure 1). 


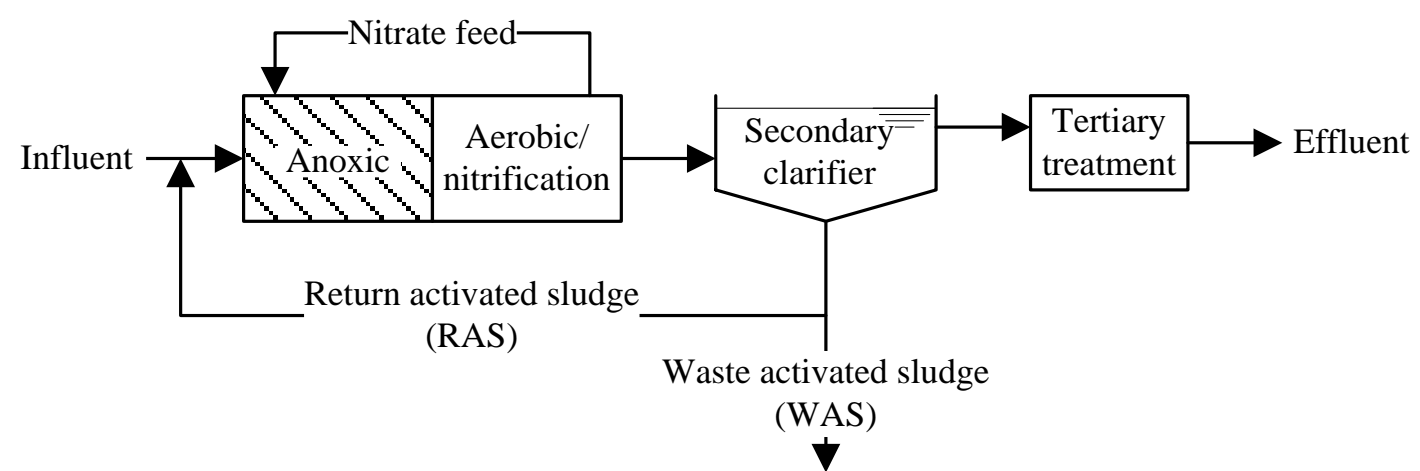

Figure 1. Schematic flow diagram of extended aeration process with nitrification/denitrification and tertiary treatment.

Together they currently treat $180 \mathrm{hm}^{3}$, and their average treatment volume is $110.48 \mathrm{hm}^{3}$ annually, which represents a population equivalent of approximately $1,615,900$.

In order to homogenize the sample, WWTPs were excluded if either 12 or more consumption figures (to eliminate seasonal variations), or all $\mathrm{BOD}_{5}$ data (both input and output) was not available. As such, an average of 19.66 months worth of data was available for each WWTP included in the study.

As part of the statistical analysis performed, the sample was segmented to reflect the size of the WWTPs using two different approaches:

1) WWTP size in terms of the average monthly treatment volume in $\mathrm{m}^{3}$.

2) WWTP size in terms of the population equivalent served.

Using the first approach (segmentation by size in terms of volume in $\mathrm{m}^{3}$ treated monthly), 11 segments were selected. The number of WWTPs in the sample belonging to each segment is shown in Figure 2.

Using the second approach (segmentation by size in terms of $\mathrm{p}$-e served), 11 segments were also selected. The number of WWTPs in the sample belonging to each segment is shown in Figure 3.

It may be appreciated that the resulting histograms for both of the proposed segmentation approaches are very similar, although it should be noted that certain
WWTPs do move from one segment to another, and that the three greatest segments have been maintained despite containing only one WWTP. This is due to their large size and hence lower energy consumption ratio.

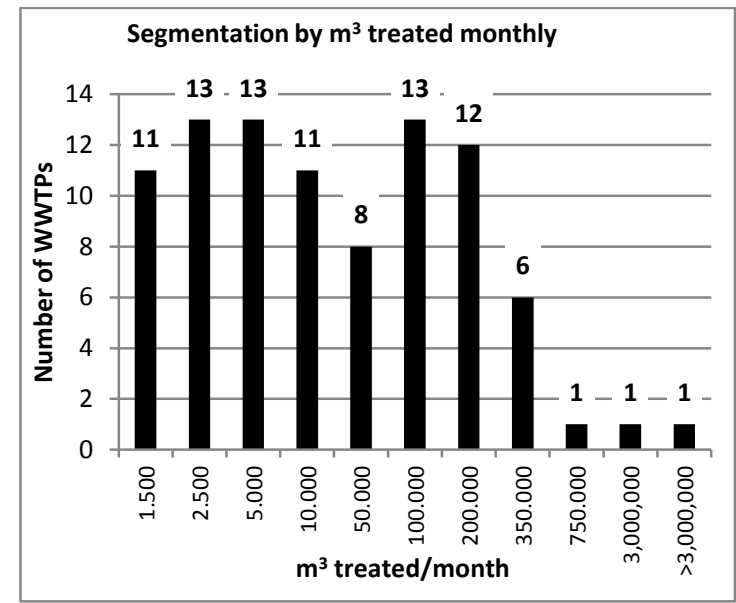

Figure 2. Histogram of $\mathrm{m}^{3}$ treated monthly ( $\mathrm{m}^{3} /$ month).

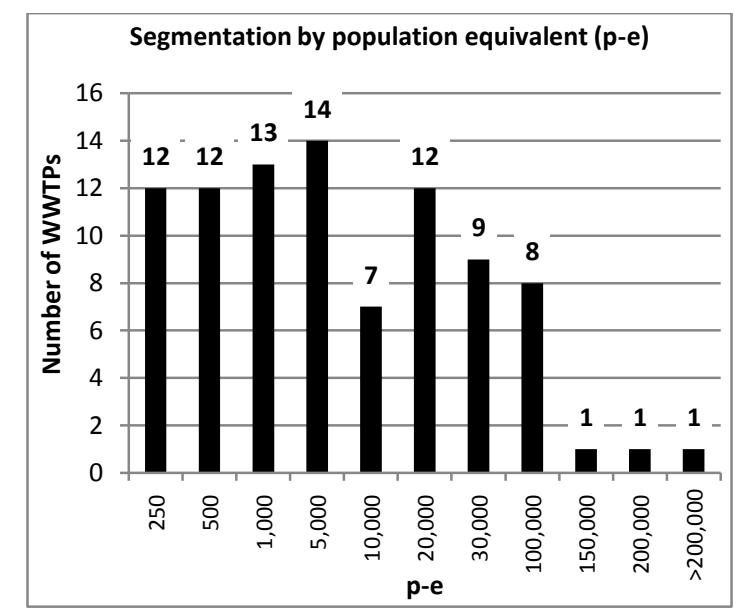

Figure 3. Histogram of population equivalent (p-e). 


\section{Results and Discussion}

For the first segmentation approach (by size in terms of volume in $\mathrm{m}^{3}$ treated monthly), the energy consumption figures obtained (in $\mathrm{kWh} / \mathrm{m}^{3}$ treated) are shown in Table 1 and Figure 4.

Table 1. Energy consumption by size in terms of treatment volume $\left(\mathrm{m}^{3} /\right.$ month).

\begin{tabular}{rrrr}
\hline $\begin{array}{c}\text { Number of } \\
\text { WWTPs }\end{array}$ & $\mathrm{m}^{3} / \mathrm{month}$ & $\mathrm{kWh} / \mathrm{m}^{3}$ & $\begin{array}{l}\text { Average } \\
\mathrm{kWh} / \mathrm{m}^{3}\end{array}$ \\
\hline 11 & 1,500 & 2.5239 & 0.5647 \\
13 & 2,000 & 2.1234 & 0.5647 \\
13 & 5,000 & 2.0712 & 0.5647 \\
11 & 10,000 & 1.7564 & 0.5647 \\
8 & 50,000 & 1.1520 & 0.5647 \\
13 & 100,000 & 0.8763 & 0.5647 \\
12 & 200,000 & 0.6786 & 0.5647 \\
6 & 350,000 & 0.5938 & 0.5647 \\
1 & 750,000 & 0.5348 & 0.5647 \\
1 & $3,000,000$ & 0.2860 & 0.5647 \\
1 & $>3,000,000$ & 0.3450 & 0.5647 \\
\hline 90 & & & 0.5647 \\
\hline
\end{tabular}

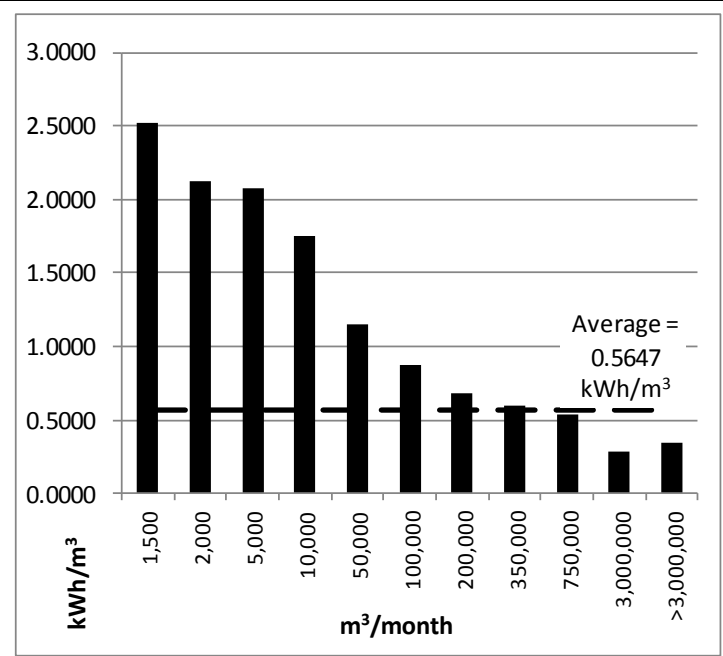

Figure 4. WWTP energy consumption: segmentation by treatment volume $\left(\mathrm{m}^{3} /\right.$ month).

It may be observed that the energy consumption of the three largest WWTPs (treatment volume greater than $350,000 \mathrm{~m}^{3}$ monthly) is below the sample average, but the consumption of the remaining 87 plants is greater than it, and that the consumption of the 37 WWTPs in the smallest three segments (treatment volume up to 5,000 $\mathrm{m}^{3} /$ month) can be 4 to 5 times the average. However, as Table 1 shows, the largest plant has a higher energy consumption $\left(0.3450 \mathrm{kWh} / \mathrm{m}^{3}\right)$ than the preceding one $\left(0.2860 \mathrm{kWh} / \mathrm{m}^{3}\right)$ and, therefore, does not follow the tendency of other segments of the table. This is explained by the fact that the latter smaller plant has fully operational cogeneration facilities, while the largest plant does not have such facilities.

It is important to note that the three largest WWTPs process more than $48 \%$ of the total treatment volume for the area studied $\left(4,443,943 \mathrm{~m}^{3}\right.$ monthly), while the 37 smallest WWTPs, whose energy consumption is extremely high, treat less than $1 \%$ of the total volume $\left(86,929 \mathrm{~m}^{3}\right.$ monthly). That is to say that their high energy consumption barely affects the average for the area studied, whose total treatment volume is $9,206,730 \mathrm{~m}^{3}$ monthly.

The energy consumption figures in $\mathrm{kWh} / \mathrm{m}^{3}$ obtained using the second segmentation approach (by size in terms of population equivalent) are shown in Table 2 and Figure 5.

Table 2. Energy consumption by size in terms of population equivalent ( $\mathrm{p}-\mathrm{e})$.

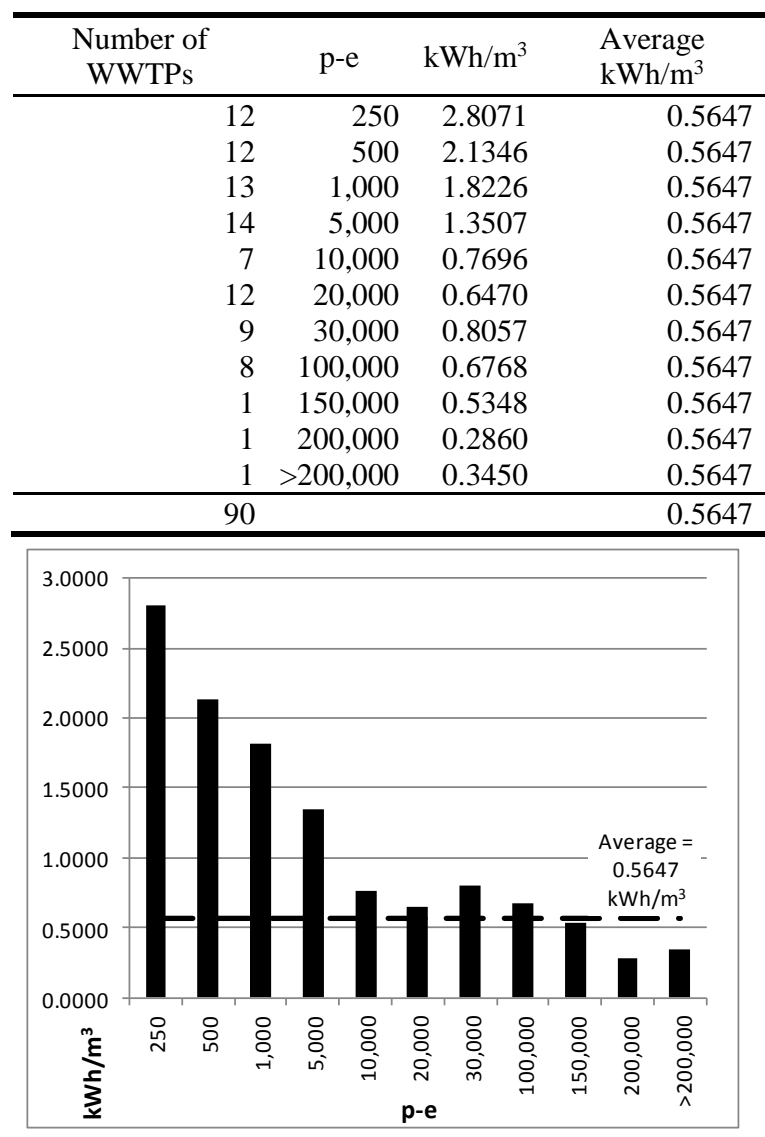

Figure 5. WWTP Energy consumption: segmentation by population equivalent (p-e) . 
It is readily observed that the energy consumption of the three largest WWTPs (population equivalent of over 100,000) is lower than the average, while that of the other 87 is above the average, and the 37 smallest WWTPs (population equivalent of up to 1,000) in some cases consume four times more energy than the average.

It must also be underlined that the three largest plants serve more than $46 \%$ of the study area's population equivalent $(742,980$ p-e), whilst the smallest (and least energy efficient) 37 WWTPs serve less than $1 \%$ of the population equivalent $(15,822 \mathrm{p}-\mathrm{e})$. This is to say that, as observed for the previous segmentation approach, the high energy consumption of the smallest WWTPs barely affects the average consumption for the area studied, where the total population equivalent is $1,615,900$.

It is evident that the total average consumption for the 90 WWTPs is not affected by the segmentation approach used. It was calculated to be 0.5647 $\mathrm{kWh} / \mathrm{m}^{3}$.

The results expressed as a function of $\mathrm{m}^{3}$ treated/month may be fitted to a parabolic curve using the least squares method (see Figure 6), whose equation is as follows:

$$
y=0.0181 x^{2}-0.4506 x+3.0467
$$

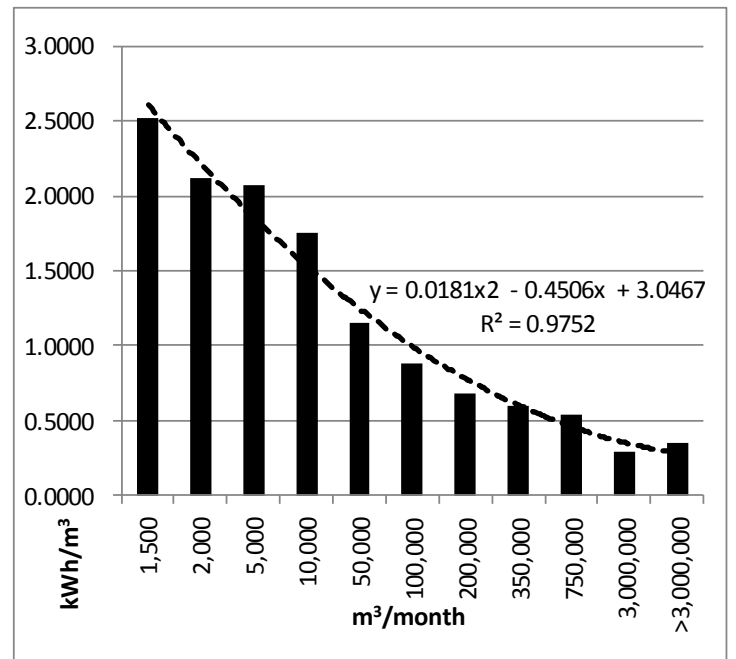

Figure 6. Fitted curve representing energy consumption ratio $\left(\mathrm{kWh} / \mathrm{m}^{3}\right)$ as a function of treatment volume $\left(\mathrm{m}^{3} / \mathrm{month}\right)$.
Using the same procedure, the results expressed as a function of population equivalent served may also be fitted to a parabolic curve (see Figure 7) with the following equation:

$$
y=0.031 x^{2}-0.5987 x+3.2715
$$

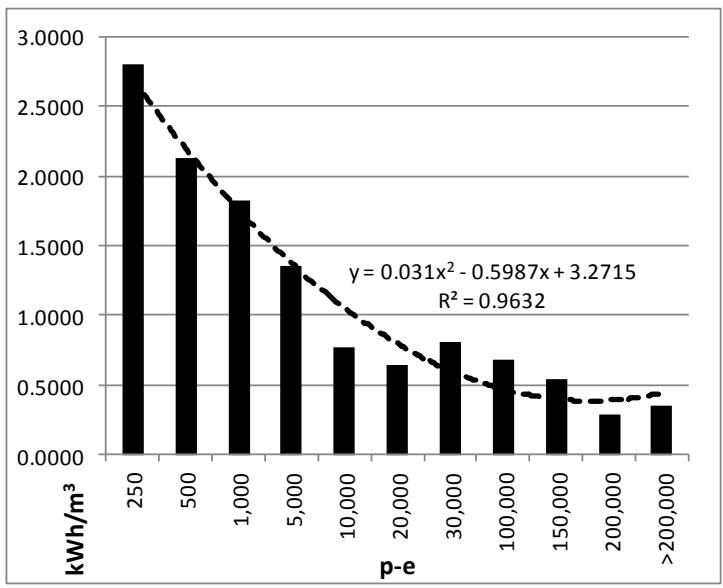

Figure 7. Fitted curve representing energy consumption ratio $\left(\mathrm{kWh} / \mathrm{m}^{3}\right)$ as a function of population equivalent served (p-e).

The respective values of the coefficient of determination in both cases tend to $1\left(R^{2}\right.$ $=0.9752$ and $\left.R^{2}=0.9632\right)$, which demonstrates not only the goodness of fit achieved, but also a high degree of correlation between the variables involved. That is, the energy consumption ratio $\left(\mathrm{kWh} / \mathrm{m}^{3}\right)$, the treatment volume $\left(\mathrm{m}^{3} / \mathrm{month}\right)$ or the population equivalent served (p-e).

The trend analysis performed allows predictions to be made regarding the consumption ratio, allowing the determination of values outside of the study sample (by extrapolation) or within the study sample (by interpolation).

\section{Conclusions}

Based on the previous discussion, the following conclusions may be drawn:

1. The increase in energy consumption ratio $\left(\mathrm{kWh} / \mathrm{m}^{3}\right)$ is proportional to the square of WWTP size decrease. This is due to the fact that the energy costs per unit for larger 
WWTPs are lower, possibly owing to the following:

a) Economy of scale and the use of cost synergies.

b) The possibility to modulate treatment processes in various different lines according to seasonal variations

c) The effective use of cogeneration systems that permit the production of electricity for use on site or sale to the grid.

2. It is advisable to design WWTPs to be as large as possible, attempting to concentrate effluent from several urban area such that the energy consumption is $1 / 3^{\text {rd }}$ that of small WWTPs. The advantages become clear when taking into account that energy costs represent more than $50 \%$ of total operation costs in a WWTP, and that this will increase in line with forecasted general increases in energy costs.

However, the economic costs associated with the transport of effluents from various urban areas (recovery of investments, expropriations, rights of way, pumping costs etc.) should not be ignored, nor the environmental costs (environmental impact of large WWTPs and their associated pipelines, possible local reuse, outflow locations etc.).

\section{Acknowledgements}

The authors wish to express their thanks for the invaluable assistance given by the Murcia Region Wastewater Sanitation and Treatment Agency (ESAMUR) in providing the data used in this study.

\section{References}

Albaladejo, A. and Trapote, A., 2013. Influencia de las tarifas eléctricas en los costes de operación y mantenimiento de las depuradoras de aguas residuales. aguas residuales.com. Available from: http://www.aguasresiduales.info/main/inde x.php?md_0 $=4 \&$ md_1 $=\& i d=3584 \& \_p a g=1$ [Accesed 27 Feb 2013].

Boletín Oficial del Estado, 1995. Real Decreto Número 11/95.

Castelll, D.; García, M.; Tormos, I.; Ferrer, C., 2011. Optimización energética del sistema de aireación de una EDAR. Análisis comparativo de dos tecnologías. Tecnología del Agua, 327, 50-56.

ESAMUR, 2010-2011. Datos técnicos de operación de las EDARs. 